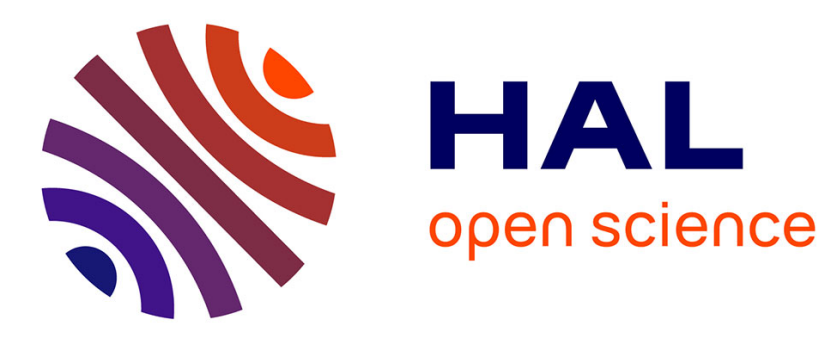

\title{
Identification and quantification of domoic acid by UHPLC/QTOF tandem mass spectrometry, with simultaneous identification of non-target photodegradation products
}

Anne-Laure Gagez, Antoine Bonnet, Philippe Pineau, Marianne Graber

\section{To cite this version:}

Anne-Laure Gagez, Antoine Bonnet, Philippe Pineau, Marianne Graber. Identification and quantification of domoic acid by UHPLC/QTOF tandem mass spectrometry, with simultaneous identification of non-target photodegradation products. International Journal of Environmental Analytical Chemistry, 2017, pp.1 - 14. 10.1080/03067319.2017.1393538 . hal-01630105

\section{HAL Id: hal-01630105 https://hal.science/hal-01630105}

Submitted on 15 Jan 2018

HAL is a multi-disciplinary open access archive for the deposit and dissemination of scientific research documents, whether they are published or not. The documents may come from teaching and research institutions in France or abroad, or from public or private research centers.
L'archive ouverte pluridisciplinaire HAL, est destinée au dépôt et à la diffusion de documents scientifiques de niveau recherche, publiés ou non, émanant des établissements d'enseignement et de recherche français ou étrangers, des laboratoires publics ou privés. 
1 Identification and quantification of domoic acid by UHPLC/QTOF tandem mass

2 spectrometry, with simultaneous identification of non-target photodegradation

6 Anne-Laure Gagez ${ }^{1}$, Antoine Bonnet ${ }^{1}$, Philippe Pineau ${ }^{1}$ and Marianne Graber ${ }^{1}$

7

$8 \quad{ }^{1}$ UMR CNRS 7266 LIENSs, Université of La Rochelle, Bâtiment Marie Curie, Avenue Michel 9 Crépeau, 17042 La Rochelle, France.

11 Dr. Anne-Laure Gagez: anne-laure.gagez@univ-lr.fr

12 Antoine Bonnet: antoine.bonnet@ univ-lr.fr

13 Philippe Pineau: philippe.pineau@univ-lr.fr

14 Pr. Marianne Graber: mgraber@univ-lr.fr

16 Corresponding author:

17 Pr. Marianne Graber

18 UMR CNRS 7266 LIENSs, Bâtiment Marie Curie

19 Avenue Michel Crépeau

$20 \quad 17042$ La Rochelle

21 France

22 mgraber@univ-lr.fr

23 phone: +33546458630

24 fax: +33546458265 
Abstract

Amnesic shellfish poisoning is a potentially lethal human toxic syndrome which is caused by domoic acid (DA), a neurotoxin produced by marine phytoplankton, principally from Pseudonitzschia genus. In this report, a method to identify and quantify the DA toxin, with simultaneous identification of its photodegradation products has been developed. It uses an Ultra High Performance Liquid Chromatography coupled to a Quadrupole-Time-Of-Flight tandem mass spectrometer (UHPLC-QTOF) after solid-phase extraction An unambiguous identification of DA was carried out by considering both the retention time of DA in UHPLC and the exact mass of protonated DA molecule $\left([\mathrm{M}+\mathrm{H}]^{+}=312.1447 \mathrm{~m} / \mathrm{z}\right)$ and of the most intense fragment ion $(\mathrm{m} / \mathrm{z}$ 266.1391), The quantification was conducted using protonated DA molecule with protonated Glafenin as internal standard, obtaining a LOD of $0.75 \mu \mathrm{g} \mathrm{L}^{-1}$. Large screening with UHPLCQTOF could also give structural informations about degradation products of DA present in samples after UV-irradiation. This method was applied for the determination of DA in complex liquid samples after solid-phase extraction, and is applicable for environmental monitoring of this toxic substance in the aquatic environment.

(3)

Keywords: Domoic Acid, Toxin, Seawater, Liquid chromatography, Mass spectrometry, Accurate mass 
Domoic acid (DA) was identified as a marine neurotoxin at the end of the 1980s following human poisoning incident in Canada, after consumption of cultured blue mussels Mytilus edulis [1]. Red algae and diatoms were found to be primary producers of DA [2], but it is the accumulation of DA in filter-feeding marine organisms which poses the biggest threat to human health. Symptoms produced by this algal toxin include, among other clinical signs, in many of the seriously intoxicated individuals, persistent short term memory loss. The syndrome was thus called amnesic shellfish poisoning (ASP) [3]. DA intoxication in wild animals, such as anchovies, sea lions, whales, sea birds and fishes, has been reported [2,4-7]. DA is a water soluble, polar, non-protein amino acid, whose chemical structure was determined by NMR [2] and then confirmed following total synthesis [8]. It consists of a proline ring, three carboxyl groups and an imino group, which leads to four chargeable groups that can exist in up to five charged states from -3 to 1 depending on the $\mathrm{pH}$ (Figure 1). At room temperature, DA is relatively stable and does not degrade [9]. At neutral $\mathrm{pH}$, DA has an absorption maximum of $242 \mathrm{~nm}$ due to its conjugated diene moiety [5]. DA elimination in the marine environment is essentially by photodegradation via sunlight mediated reactions [10]. DA has at least nine geometrical isomers. Among them isodomoic acids D, E and F and the 5'-epi-domoic acid have been isolated from plankton cells and shellfish tissue and have been found to be less toxic than DA [11]. To protect human health and seafood safety, the European Union has established that total DA content must not exceed $20 \mu \mathrm{g} \mathrm{DA} / \mathrm{g}$ in the edible parts of molluscs [12]. This limit is employed worldwide for harvesting and consumption of shellfish resources to protect human health [13]. Numerous liquid chromatographic methods with ultraviolet diode array detection (HPLC-UVD) can be used following extraction of DA from homogenised tissue by solvent and SPE (solid phase extraction) clean-up [14]. The diene chromophore of DA permits its detection by HPLC-UVD at concentrations as low as $4-80 \mu \mathrm{g} \mathrm{L}^{-1}$ depending on the sensitivity of the detector [15]. To further 
after derivatisation has been developed in research laboratories for monitoring DA in seafood and marine phytoplankton [13]. Indeed a laboratory culture of diatom genus Pseudonitschia produces DA at levels ranging from 1 to $20 \mathrm{pg} /$ cell, with less than $1 \mu \mathrm{g} \mathrm{L^{-1 }}$ found in the culture medium [16]. In both HPLC-UVD and HPLC-FLD methods, DA is identified based on the coincidence of LC retention time of the suspected chromatographic peaks, with those of DA standard peaks; however, the suspected toxin peaks may represent compounds other than DA. An unambiguous method such as LC-mass spectrometry (LC-MS) must be used to confirm the presence of DA, especially for newly suspected source organisms or for confirming the appearance of DA in a new geographical region. So, even if HPLC-UV methods is often the only analytical tool available in many research institutes and regulatory agencies responsible for monitoring the occurrence of DA, many mass spectrometry methods were developed in different research laboratories $[14,17,18,19]$.

Moreover for researchers, the development of very sensitive methods to determine DA in seawater is still a challenge. Indeed the role of dissolved DA in seawater, its distribution patterns across the trophic webs and its production by minimally toxic phytoplankton species are not fully understood. This study describes a method for unequivocal confirmation of DA and its quantitative analysis in cell energies. The correlation of product to precursor ions is achieved, after deconvolution, by using 
fragmentation information is obtained in advance for all compounds in a single run, it was possible to simultaneously quantify DA and identify non-target degradation products of DA after UVirradiation in a single run. This UV treatment was performed in order to simulate in vitro natural sun degradation of DA. This constitutes a real novelty, offered by the possibility of performing retrospective full data examination, without re-injecting sample.

\section{Experimental}

\subsection{Chemicals and Reagents}

Domoic acid (DA) (powder form stored at $-20^{\circ} \mathrm{C}$ ) and formic acid (FA) were purchased from VWR International LLC (Radnor, PA, USA). Leibovitz's L-15 medium and fetal bovine serum (FBS, S1520-500) were from Sigma (Steinheim, Germany).

\subsection{Extraction of DA from liquid samples by SPE}

Oasis ${ }^{\circledR}$ HLB, Hydrophilic-Lipophilic-Balanced, 1 cc Vac Cartridge, 30 mg Sorbent per Cartridge (Waters, Milford, USA) was used for extraction. The choice of this cartridge was also based on $\mathrm{pH}$ stability from 0 to 14 , absence of silanol interactions, and large use for acid, base and neutral compounds extraction. Leibovitz's L-15 culture medium, which contains many amino acids, vitamins and salts, supplemented with $10 \%(\mathrm{v} / \mathrm{v})$ foetal bovine serum was used as complex liquid medium, to optimize SPE step. Samples were first spiked with $200 \mu \mathrm{g} \mathrm{L}^{-1}$ of DA, then acidified with $2 \%$ FA, vortex-mixed,centrifuged $10 \mathrm{~min}$ at 10,000 $\mathrm{g}$ and submitted to SPE. No vacuum was applied during sample loading to ensure optimal binding of DA on sorbent. During following steps of extraction, the vacuum was kept approximately at $-17 \mathrm{kPa}$. An optimized HLB cartridge protocol was applied as follows: the cartridge was first conditioned with $1 \mathrm{~mL}$ of methanol $(\mathrm{MeOH})$ and $1 \mathrm{~mL}$ of water containing $2 \%$ FA. Afterwards, $1 \mathrm{~mL}$ of sample previously acidified with $2 \%$ of FA was loaded and washed with $1 \mathrm{~mL}$ of $\mathrm{H}_{2} \mathrm{O}$. Finally, DA was eluted with $1 \mathrm{~mL}$ of $\mathrm{MeOH}: \mathrm{H}_{2} \mathrm{O}$ (40:60, v/v) with $2 \%$ FA. Then $85 \mu \mathrm{L}$ of the eluate were transferred to ultra high performance liquid 
123 chromatography (UHPLC) vials containing $15 \mu \mathrm{L}$ of Glafenin (GLF) (5 mg/L) as the internal 124 standard (IS). To investigate the efficiency of the SPE method for DA, RE (Recovery of the 125 Extraction) was determined by comparing the mean peak areas of replicate analyses $(n=5)$ of DA 126 quantification (ratio of DA to IS) obtained before and after SPE extraction (DA spiked at $200 \mu \mathrm{g} \mathrm{L-}$ 127 1), as described by Matuszewski [20]. Assessment of ME (Matrix Effect) was realized by 128 comparing the mean peak area of replicate analyses $(n=5)$ of DA quantification (ratio of DA to IS) 129 obtained in culture medium spiked with DA and IS after SPE extraction and in neat solution 130 standards, as described by Matuszewski [20].

$131 \quad 2.3$. Salinity measurement

132 Artificial seawater $(33 \mathrm{~g} / \mathrm{L})$ was prepared with ready-to-use sea salt containing all 70 trace elements 133 found in natural seawater (Tropic Marin ${ }^{\circledR}$, Wartenberg, Germany). One part of this artificial 134 seawater solution was spiked with DA (final concentration $340 \mu \mathrm{g} \mathrm{L}^{-1}$ ) to constitute the sample, and 135 the other part constituted the control. SPE was performed such as previously described in paragraph 1362.2 with salvage of each liquid fraction getting through the SPE cartridge.

137 Salinity and temperature were measured by a conductivity meter Cond 3110 with standard 138 conductivity measuring cell TetraCon 325 (WTW, Germany). Conductivity measuring cell was 139 immersed in a tube with $7 \mathrm{ml}$ of replicate and after 1 minute for stabilization.

\subsection{Photodegradation of DA}

142 Photodegradation of DA was obtained by irradiating a solution of $340 \mu \mathrm{g} \mathrm{L}^{-1} \mathrm{DA}$ in artificial sea 143 water, in glass container without lid with UV radiation at $254 \mathrm{~nm}, 6 \mathrm{~W}, 710 \mu \mathrm{W} / \mathrm{cm}^{2}$. The UV lamp 144 was from Vilber Lourmat (Torcy, France). The irradiation experiments were conducted for $3 \mathrm{~h}$ with 145 the control sample kept in the dark.

148 Analyses were performed using an Acquity UPLC H-Class (Waters, Milford, USA) coupled to a 
Xevo G2 S Q-TOF mass spectrometer equipped with an electrospray ionization (ESI) source. The

150 chromatographic system consisted of a quaternary pump (Quaternary Solvent Manager) and an 151 autosampler (Sample Manager-FTN) equipped with a $10 \mu \mathrm{L}$ sample loop. $5 \mu \mathrm{L}$ of the sample was 152 injected into a Waters Acquity UPLC BEH C18 column (2.1 x $50 \mathrm{~mm}, 1.7 \mu \mathrm{m})$. The system was 153 operated under the following gradient elution program: solution $\mathrm{A}\left(0.01 \% \mathrm{FA}\right.$ in $\left.\mathrm{H}_{2} \mathrm{O}\right)$ in solution $\mathrm{B}$ $154(0.01 \% \mathrm{FA}$ in $\mathrm{MeOH})$ at a flow rate of $300 \mu \mathrm{L} / \mathrm{min}$ as follows: $0-0.2 \mathrm{~min}, 3 \% \mathrm{~B}$; 0.2-0.25 min, $3-$ $15520 \% \mathrm{~B} ; 0.25-1 \mathrm{~min}, 20-55 \% \mathrm{~B} ; 1-1.5 \min , 55-100 \% \mathrm{~B} ; 1.5-3.5 \mathrm{~min}, 100 \% \mathrm{~B} ; 3.5-3.6 \min , 100-3 \%$ $156 \mathrm{~B} ; 3.6-4.5 \mathrm{~min}, 3 \% \mathrm{~B}$. The column and the autosampler were maintained respectively at $+25^{\circ} \mathrm{C}$ and $157+7^{\circ} \mathrm{C}$.

158 ESI was shown as the optimum ion source interface for DA analysis [21]. Optimization of mass 159 spectrometry parameters was performed in two steps: first, by direct infusion of DA at constant flow 160 of $20 \mu \mathrm{L} \mathrm{min}^{-1}$ and second, by infusion combined with liquid chromatography flow equal to $50 \mu \mathrm{L}$ $161 \mathrm{~min}^{-1}$. Final ESI conditions were: source temperature $120^{\circ} \mathrm{C}$, desolvation temperature $500^{\circ} \mathrm{C}$, cone 162 gas flow $50 \mathrm{~L} \mathrm{~h}^{-1}$, desolvation gas flow $1000 \mathrm{~L} \mathrm{~h}^{-1}$, capillary voltage $2.5 \mathrm{kV}$, sampling cone 35 and 163 source offset 80 . The instrument was set to acquire over the $\mathrm{m} / \mathrm{z}$ range $50-1200$ with a scan time 164 equal to $0.15 \mathrm{~s}$. These conditions gave a resolution equal to 30000 for protonated DA molecule $165\left([\mathrm{M}+\mathrm{H}]^{+}=312.1447 \mathrm{~m} / \mathrm{z}\right.$. Data were collected in the positive (ESI+) electrospray ionization modes. 166 The MS and the MS/MS experiments were performed using the $\mathrm{MS}^{\mathrm{E}}$ function in centroid mode. A $167 \mathrm{MS}^{\mathrm{E}}$ approach consists in MS and MS/MS data acquisitions in a single same run, with no collision 168 energy in function 1 (MS experiment) and a collision energy ramp of 15-45 V in function 2 169 (MS/MS experiment). Leucine Enkephalin $\left([\mathrm{M}+\mathrm{H}]^{+}=556.2771 \mathrm{~m} / \mathrm{z}\right)\left(1 \mathrm{ng} \mu \mathrm{L}^{-1}\right)$ was used as lock 170 mass for mass shift correction. The mass spectrometer was calibrated before analyses using $0.5 \mathrm{mM}$ 171 sodium formate solution.

172 DA quantitation was obtained by calibration curve of DA standard reference at the following 173 concentrations: $2.5,5,10,25,50,100,250,500,1000 \mu \mathrm{g} \mathrm{L}^{-1}$, prepared by cascade dilution in $174 \mathrm{MeOH}: \mathrm{H}_{2} \mathrm{O}(40: 60$, v/v) with 2\% FA before each run. After vortex-mixing, $85 \mu \mathrm{L}$ of each standard 
was transferred to UHPLC vials containing $15 \mu \mathrm{L}$ of GLF $\left(5 \mathrm{mg} \mathrm{L}^{-1}\right)$ as internal standard.

\subsection{Analytical validation}

Intraassay precision was studied by preparing and analysing five independent replicates of DA quality controls prepared as described above at different concentrations (20,40,80, 200, 400, and $800 \mu \mathrm{g} \mathrm{L}^{-1}$ ) on a given day. Interassay precision and linearity were evaluated from the analysis of a calibration set each day during 5 days.

To evaluate the stability of DA in $\mathrm{MeOH}: \mathrm{H}_{2} \mathrm{O}(40: 60$, v/v) with $2 \% \mathrm{FA}$, that correspond to the injection conditions of DA, extraction of DA was performed as described in 2.2. One aliquot of elution was analysed immediately. Four aliquots of the same sample supernatant were kept at $+7^{\circ} \mathrm{C}$ in the autosampler for $6 \mathrm{~h}$ and $22 \mathrm{~h}$, at $+4^{\circ} \mathrm{C}$ in a refrigerator for 4 days and 15 days and at $-20^{\circ} \mathrm{C}$ in a deep-freeze for $24 \mathrm{~h}$ prior to analysis. A sixth aliquot was used to study the stability of DA over three freeze $\left(-20^{\circ} \mathrm{C}\right)$-thaw (room temperature) cycles. Three replicates of each aliquot were analysed and compared with independently and extemporaneously prepared calibration curves with DA in powder form stored at $-20^{\circ} \mathrm{C}$. The mean concentration of DA immediately analysed in triplicate was used as control for comparison with other samples.

\subsection{Data analysis}

Post-acquisition analyses were performed using the MassLynx ${ }^{\mathrm{TM}}$ V4.1 program (Waters, Milford, USA). Using ChromaLynx ${ }^{\mathrm{TM}}$ application, compounds were first identified based on their retention time, mass accuracy and fragment confirmation. Then, positively identified compounds in each sample were transferred to quantification using the software TargetLynx ${ }^{\mathrm{TM}}$. The MetaboLynx ${ }^{\mathrm{TM}}$ application automates the process of peak detection, comparison of data between DA control sample and DA sample after photodegradation and also for filtering the matrix-related peaks. Peaks only present in DA sample after photodegradation are considered as molecules produced by transformation of parent. MetaboLynx ${ }^{\mathrm{TM}}$ software used elemental composition to suggest formula 
of degradation products. Elemental composition parameters were: 5 ppm mass tolerance, with 0 to

20250 for the number of carbon atoms, from 0 to 100 for the number of hydrogen atoms, from 0 to 20

203 for the number of nitrogen atoms, from 0 to 20 for the number of oxygen atoms and from 0 to 1 for 204 the number of sodium atoms.

3. Results and discussion

\subsection{Fragmentation of DA standard}

209 Ionization of DA was better in positive mode than in negative mode and MS conditions were optimized (see detailed values in 2.3 "Material and methods"). DA identification was confirmed by

211 MS and MS/MS fragmentation patterns (Fig. 2). Full mass spectra from DA standard shows the 212 major molecular ion for the toxin at $\mathrm{m} / \mathrm{z} 312.1447[\mathrm{M}+\mathrm{H}]^{+}$, and a peak at $\mathrm{m} / \mathrm{z} 334.1263$ is attributed 213 to the $[\mathrm{M}+\mathrm{Na}]^{+}$sodium adduct ion. The fragmentation profile produced in high collision energy 214 function consists mainly in water $\left(\mathrm{H}_{2} \mathrm{O}\right)$, formic acid $\left(\mathrm{CH}_{2} \mathrm{O}_{2}\right)$ and $\mathrm{CO}$ losses (Fig. 2). Table 1 215 displays elemental composition, corresponding fragmentation or adduct ion, theoretical mass, 216 measured mass and mass errors in ppm of reference DA and its major fragment ions. The maximum 217 mass errors between theoretical and observed values were less than $5 \mathrm{ppm}$, which means high 218 resolution and good accuracy of measures by theselected method.

219 Exact mass of the fragmentation of the $[\mathrm{M}+\mathrm{H}]^{+}$adduct ion of DA is detailed in Table 1 and Fig. $2 \mathrm{~B}$. 220 The most intense fragment ion ( $\mathrm{m} / \mathrm{z} 266.1391)$ of DA is due to the loss of a $\mathrm{H}_{2} \mathrm{O}$ molecule (18 Da). 221 Based on this information, the different fragmentation pathways of DA are proposed in Fig. 3.

222 Results obtained by exact mass measurements coincide with those reported by other authors using 223 single quadrupole [22], ion-trap single quadrupole [17,23,24], or triple quadrupole with [13,15,25] or without trap technology [21] mass spectrometer. 
Efficient separation of DA and GLF from impurities was performed in 4.5 minutes. Peaks of DA and GLF were in the middle of the chromatogram, with retention times respectively equal to 2.22 and $2.39 \mathrm{~min}$ (Fig.4)Column temperature was tested, from $+25^{\circ} \mathrm{C}$ to $+80^{\circ} \mathrm{C}$, with a step of $+5^{\circ} \mathrm{C}$. No significant difference in DA quantification was observed, except at $+80^{\circ} \mathrm{C}$ where the analyte started to be degraded (data not shown).

In several previous studies the column temperature chosen for liquid chromatographic separation was between $+40^{\circ} \mathrm{C}$ and $+70^{\circ} \mathrm{C}[13,15,21,25]$ but with our system, heating the column above $25^{\circ} \mathrm{C}$ did not increase the detection nor the quantification limits of DA. The temperature of $+25^{\circ} \mathrm{C}$ was thus adopted.

Mass spectrometer parameters were first optimized by injecting standard reference solution of DA in infusion mode and finalized in combined mode, namely by using a combination of infusion mode with an UHPLC flux (0.05 mL/min.). Generally, for small molecules, the best tension capillary is $0.5 \mathrm{kV}$ in combined mode, but for DA detection, better response was obtained with $2.5 \mathrm{kV}$, close to value used in infusion mode, $3 \mathrm{kV}$. DA identification was possible in both positive and negative mode, but positive mode was more sensitive.

DA was identified from $\mathrm{MS}^{\mathrm{E}}$ acquisition data by together its retention time (2.22 min.), its mass accuracy given by the elemental composition $\left(\mathrm{C}_{15} \mathrm{H}_{21} \mathrm{NO}_{6}{ }^{+}\right)$and one chosen fragment $(\mathrm{m} / \mathrm{z}$ 266.1392) corresponding to elemental composition $\mathrm{C}_{14} \mathrm{H}_{20} \mathrm{NO}_{4}{ }^{+}$to confirm the presence of the molecule. For GLF identification, both retention time (2.39 min.) and mass accuracy $\left(\mathrm{C}_{19} \mathrm{H}_{18} \mathrm{~N}_{2} \mathrm{O}_{4} \mathrm{Cl}^{+}\right):[\mathrm{M}+\mathrm{H}]^{+}=373.0955 \mathrm{~m} / z$ were used. Integration parameters were optimized and mean function was chosen as smoothing method. Itconsists in taking the arithmetical mean of the intensities of the data points in each window along the chromatogram. Identified analytes were quantified using GLF as internal standard. 
before SPE. This allowed a complete retention of DA on the SPE cartridge, while eluting unretained matrix, with a wash step using $100 \%$ water. To finalize the elution step of DA, an optimization approach was used, using 20 different mixtures as elutant solutions, containing $2 \%$ FA or $2 \%$ ammonium hydroxide $(\mathrm{AH})$ in $\mathrm{MeOH}: \mathrm{H}_{2} \mathrm{O}$ mixtures with increasing $\mathrm{MeOH}$ amounts. $\mathrm{MeOH}: \mathrm{H}_{2} \mathrm{O}$ (40:60, v/v) with $2 \%$ FA solution was selected to be the best elutant solution. It was just strong enough to elute DA while retaining the most hydrophobic interferences on the sorbent. In these conditions, RE of DA was equal to $96 \pm 2 \%$, which corresponds to an excellent recovery of DA. ME was equal to $95 \pm 2 \%$. This value indicates very slight ionization suppression in the extract compared to the neat solution.

\subsection{Desalination of sample by solid-phase extraction}

Removing salt in sample before analysis without loss of the molecules of interest is essential for subsequent mass spectrometry. The measure of salinity was performed at each step of the solid phase extraction. The salt concentration in both starting samples (control: artificial sea water and sample: artificial sea water $+0.34 \mathrm{ng} / \mu \mathrm{L} \mathrm{DA}$ ) was equal to $28.7 \mathrm{~g} / \mathrm{L}$. The salts were recovered almost entirely in the "load fraction", respectively at 27.8 and $27.7 \mathrm{~g} / \mathrm{L}$, showing that the SPE cartridge did not retained salts on the column. The salinity of the "wash" and "elution" fractions were measured with the conductivity meter Cond 3110. They contained respectively salt concentrations equal to 0.7 and $0.5 \mathrm{~g} / \mathrm{L}$, showing that the SPE allowed an almost complete desalinisation of the samples.

\subsection{Analytical validation}

Calibration curve obtained using linear regression with a weighting factor of $1 / \mathrm{x}^{2}$ gave regression correlation coefficients $\mathrm{R}^{2}=0.994$. The quantification method showed good intraassay precision, with mean relative error (MRE) less than $17.4 \%$ and relative standard deviation (RSD) always less than $7.4 \%$. Interessay precision was also good over the concentration range, with MRE inferior to 
280 DA compound was found to be stable in its injection solvent (MeOH: $\mathrm{H}_{2} 0$ (40:60, v/v) with 2\% FA) 281 for at least 15 days at $+4^{\circ} \mathrm{C}$ and at least $24 \mathrm{~h}$ at $-20^{\circ} \mathrm{C}$ and to tolerate three freeze/thaw cycles, with 282 maximal deviation from initial time equal to $16.6 \%, 7.7 \%$ and $10.2 \%$ respectively . The stability of 283 DA in the autosampler at $+7^{\circ} \mathrm{C}$ was demonstrated over $22 \mathrm{~h}$, with $2.9 \%$ maximal deviation 284 compared to initial time.

285 The mean signal/noise ratio $(\mathrm{S} / \mathrm{N})$ was obtained thanks to software TargetLynx ${ }^{\mathrm{TM}}$, by using 10 286 different blank injections. Limits of detection (LOD) was then estimated on the basis of signal/noise 287 ratio $(\mathrm{S} / \mathrm{N})$ of three, by injecting solutions with lower and lower DA concentrations. LOD was 288 found to be equal to $0.75 \mu \mathrm{g} \mathrm{L}^{-1}$. This detection limit value, with Q-TOF method was lower than UV 289 detection (4-80 $\mu \mathrm{g} \mathrm{L}^{-1}$, depending on the sensitivity of the detector [15]), because of the sensitivity 290 and the specificity of the mass detector, and without false positives commonly encountered with UV 291 method. It was also better than MS single quad or orbitrap detection and was equivalent with the 292 LOD obtained with triple-quadrupole MS) [26, 27, 28]. Furthermore, the disadvantage of these 293 SRM or MRM scanning acquisitions is the impossibility to visualize other ions than those isolated 294 as precursor ion prior to the analysis. In the present case however, with $\mathrm{MS}^{\mathrm{E}}$ data acquisitions used 295 with Q-TOF, all analytes in sample are detected and saved, including all precursors and their 296 fragments. This allowed to perform the following additional investigation about DA 297 photodegradation products, by reprocessing the data, without performing a new sample injection.

298 3.6. Identification of DA photodegradation products

299 UV-irradiation of DA induced the appearance of several peaks after extraction at $\mathrm{m} / \mathrm{z} 312.14 \pm 0.02$ 300 Da (Fig. 5), that potentially corresponded to degradation products of DA. MetaboLynx ${ }^{\mathrm{TM}}$ analysis 301 allowed to identify geometrical isomers of DA based on their measured mass (Table 2, expected 302 products). Fragmentation pattern of these molecules was then manually confirmed from $\mathrm{MS}^{\mathrm{E}}$ data, 303 which was similar to the parent DA (Fig.2). Regarding unexpected products coming from 304 photodegradation of DA, two peaks appeared significant in irradiated sample compared to control. 
For each of these peaks, many possibilities of elemental composition were proposed by the software

306 (Table 2, unexpected products). With i-FIT values linked to a proposed elemental composition for a 307 given measured mass, from mass error ( $\mathrm{ppm})$, retention time (2.54 min.) and assumingimpossible 308 incorporation of more than one nitrogen, the list of proposed elemental composition diminished to 309 finally go to decarboxylated molecules of DA: $\mathrm{C}_{14} \mathrm{H}_{22} \mathrm{NO}_{4}{ }^{+}\left(\mathrm{m} / \mathrm{z}\right.$ 268.1550) and $\mathrm{C}_{14} \mathrm{H}_{21} \mathrm{NO}_{4} \mathrm{Na}^{+}$ $310(\mathrm{~m} / \mathrm{z} 290.1368)$.

311 Precursor ion informations with fragment analysis $\mathrm{MS}^{\mathrm{E}}$ (MetaboLynx ${ }^{\mathrm{TM}}$ ) gave complete 312 visualisation of affiliation parent-daughter and daughter-parent ions. Fragment ions combined with 313 elemental composition searched on spectra allowed to determine the photodegradation products 314 (Table 3). The software could also give the probability of the position of the transformation by 315 photodegradation of DA, which allow the structure shown on Figure 6 to be proposed.. Indeed, each 316 major fragment ions of photodegradation product of DA corresponded to the major fragment ions of 317 DA with a loss of $\mathrm{CO}_{2}(\mathrm{~m} / \mathrm{z} 43.9898)$. For confirmation of the decarboxylated of DA, a MS/MS 318 analysis was realized on $\mathrm{m} / \mathrm{z} 268.15$ (Figure 7). All major fragment ions of the decarboxylated 319 molecule were found. Thus, the algorithm used allowed the detection and identification of unknown 320 degradation product, after extraction of ion chromatograms for expected transformation products, 321 based on predicted or unpredicted molecular changes relative to the parent compound DA.

322 This result is in accordance with previous studies, in which exposure of DA to sunlight modified its 323 chemical structure and produced a suite of isomers (isodomoic acids D, E, or F) and products 324 tentatively identified as decarboxylated derivatives [28]. More recently, the presence of a DA 325 photodegradation product corresponding to a decarboxylation product of DA $\left([\mathrm{M}+\mathrm{H}]^{+}=268\right)$ was 326 observed in seawater matrices, after exposure to a solar simulator [29]. In the same study, it was 327 shown that high halides concentrations in sea water increased DA photodegradation and altered its 328 transformation pathway, with the production of a predominant, but unidentified, product $\left([\mathrm{M}+\mathrm{H}]^{+}=\right.$ 329 344). This product was not recovered in the present case.

330 4. Conclusion 
331 The proposed UHPLC-ESI- Quadrupole-Time-Of-Flight tandem mass spectrometry MS ${ }^{\mathrm{E}}$ method 332 after SPE is a useful tool for the rapid and sensitive detection and structural characterization of DA 333 from complex samples. UHPLC gives higher separation efficiency and resolution with much lower 334 solvent consumption than classic HPLC. Q-TOF mass spectrometer allows an unambiguous 335 identification of researched analytes with exact mass determination and simultaneous quantification 336 of DA with a LOD equal to $0.75 \mu \mathrm{g} \mathrm{L}^{-1}$. Moreover, supplementary post-acquisition treatment can be 337 performed to find possible DA transformation products, thanks to specific $\mathrm{MS}^{\mathrm{E}}$ acquisition mode of 338 Q-TOF mass spectrometer. This therefore could be an important tool for routine analysis of DA in 339 complex matrices and for the environmental monitoring of this toxic substance in the aquatic 340 environment. 
Acknowledgements.

342 This study was funded by the CPER "Plateforme Littoral" sub-action "Valorisation 343 Biotechnologique des ressources marines littorales" and the Programme Opérationnel FEDER 344 2007-2013, « Compétitivité Régionale et Emploi » Poitou-Charentes.

References

[1] T. M. Perl, L. Bédard, T. Kosatsky, J. C. Hockin, E. C. Todd and R. S. Remis, N. Engl. J. Med. 349 322, 1775 (1990).

[2] K. A. Lefebvre and A. Robertson, Toxicon 56, 218 (2010).

[3] O. M. Pulido, Mar. Drugs 6, 180 (2008).

[4] K. A. Lefebvre, S. Bargu, T. Kieckhefer and M. W. Silver, Toxicon 40, 971 (2002).

[5] K. A. Lefebvre, C. L. Powell, M. Busman, G. J. Doucette, P. D. Moeller, J. B. Silver, P. E.

[6] C. A. Scholin, F. Gulland, G. J. Doucette, S. Benson, M. Busman, F. P. Chavez, J. Cordaro, R.

DeLong, A. De Vogelaere, J. Harvey, M. Haulena, K. Lefebvre, T. Lipscomb, S. Loscutoff, L. J.

Silvagni, M. Silver, T. Spraker, V. Trainer and F. M. Van Dolah, Nature 403, 80 (2000).

[7] A. Sierra Beltrán, M. Palafox-Uribe, J. Grajales-Montiel, A. Cruz-Villacorta and J. L. Ochoa,

[8] Y. Ni, K. K. D. Amarasinghe, B. Ksebati and J. Montgomery, Org. Lett. 5, 3771 (2003).

[9] J. N. Johannessen, J. AOAC Int. 83, 411 (2000).

[10] R.-C. Bouillon, T. L. Knierim, R. J. Kieber, S. A. Skrabal and J. L. C. Wright, Limnol. 
375 [11] M. A. Quilliam, in: G.M. Hallegraeff and D.M. Anderson, A.D. Cembella (Eds.), Manual on 376 Harmful Marine Microalgae, Monographs on Oceanographic Methodology, 11, Paris, pp.247 377 (2003).

[12] EU, Commission of the European Communities 97/61/CE, Off. J. Eur. Commun. L295, 35 380 (1995).

[13] Z. Wang, K. L. King, J. S. Ramsdell and G. J. Doucette, J. Chromatogr. A 1163, 169 (2007).

[14] Y. He, A. Fekete, G. Chen, M. Harir, L. Zhang, P. Tong and P. Schmitt-Kopplin, J. Agric. Food 385 Chem. 58, 11525 (2010).

[15] L. L. Mafra Jr, C. Léger, S. S. Bates and M. A. Quilliam, J. Chromatogr. A 1216, 6003 (2009). 388

[16] S.S. Bates, A.S.W. de Freitas, J.E. Milley, R. Pocklington, M.A. Quiliam, J.C. Smith and J. 390 Worms, Can. J. Fish. Aquat. Sci. 48, 1136 (1991).

[17] A. Furey, M. Lehane, M. Gillman, P. Fernandez-Puente and K. J. James, J. Chromatogr. A 393 938, 167 (2001).

[18] E. Barbaro, R. Zangrando, S. Rossi, W. R. Cairns, R. Piazza, F. Corami, C. Barbante and A. 397

[19] Z. Zendong, P. Mccarron Pearse, C. Herrenknecht, M. Sibat, Z. Amzil, R.B. Cole and P. Hess, J. Chromatogr. A 1416, 10 (2015).

[22] P. R. Costa, R. Rosa, A. Duarte-Silva, V. Brotas and M. A. M. Sampayo, Aquat. Toxicol. 74, 82 405 (2005).

[21] O. Pardo, V. Yusà and N. L. A. Pastor, J. Chromatogr. A 1154, 287 (2007).

[23] P. Ciminiello, C. Dell'Aversano, E. Fattorusso, M. Forino, G. S. Magno, L. Tartaglione, M. A. Quilliam, A. Tubaro and R. Poletti, Rapid Commun. Mass SP 19, 2030 (2005). 
410 [24] A. López-Rivera, B. A. Suárez-Isla, P. P. Eilers, C. G. Beaudry, S. Hall, M. Fernández Amandi, 411 A. Furey and K. J. James, Anal. Bioanal. Chem. 381, 1540 (2005).

412

413 [25] P. de la Iglesia, G. Giménez and J. Diogène, J. Chromatogr. A 1215, 116 (2008).

414

415 [26] P. Blay, J. P. M. Hui, J. Chang, J. E. Melanson, Anal. Bioanal. Chem. 400, 577 (2011).

416

417 [27] Y. He, A. Fekete, G. Chen, M. Harir, L. Zhang, P. Tong, P. Schmitt-Kopplin, J. Agric. Food 418 Chem. 58, 11525 (2010).

419

420

421

422

423

424

[28] R.-C. Bouillon, R.J. Kieber, S.A. Skrabal and J.L.C.Wright, Mar. Chem. 110, 18 (2008).

[29] K.M. Parkera and W.A. Mitcha, PNAS 113, 5868 (2016). 
425 Table 1. Accurate mass measurements of domoic acid and its major fragment ions.

\begin{tabular}{|c|c|c|c|c|}
\hline Elemental composition & Fragmentation/Adduct ion & $\begin{array}{c}\text { Theorical mass } \\
\mathbf{m} / \mathbf{z}\end{array}$ & $\begin{array}{c}\text { Measured mass } \\
\mathbf{m} / \mathbf{z}\end{array}$ & $\begin{array}{l}\text { Error } \\
(\mathbf{p p m})\end{array}$ \\
\hline $\mathrm{C}_{15} \mathrm{H}_{22} \mathrm{NO}_{6} \mathrm{Na}^{+}$ & $\mathrm{M}+\mathrm{H}+\mathrm{Na}]^{+}$ & 334.1266 & 334.1263 & -0.9 \\
\hline $\mathrm{C}_{15} \mathrm{H}_{22} \mathrm{NO}_{6}^{+}$ & {$[\mathrm{M}+\mathrm{H}]^{+}$} & 312.1447 & 312.1447 & 0.0 \\
\hline $\mathrm{C}_{15} \mathrm{H}_{20} \mathrm{NO}_{5}^{+}$ & {$\left[\mathrm{M}+\mathrm{H}-\mathrm{H}_{2} \mathrm{O}\right]^{+}$} & 294.1342 & 294.1339 & -1.0 \\
\hline $\mathrm{C}_{14} \mathrm{H}_{20} \mathrm{NO}_{4}{ }^{+}$ & {$\left[\mathrm{M}+\mathrm{H}-\mathrm{CH}_{2} \mathrm{O}_{2}\right]^{+}$} & 266.1392 & 266.1391 & -0.4 \\
\hline $\mathrm{C}_{14} \mathrm{H}_{18} \mathrm{NO}_{3}{ }^{+}$ & {$\left[\mathrm{M}+\mathrm{H}-\mathrm{CH}_{4} \mathrm{O}_{3}\right]^{+}$} & 248.1287 & 248.1283 & -1.6 \\
\hline $\mathrm{C}_{13} \mathrm{H}_{18} \mathrm{NO}_{2}^{+}$ & {$\left[\mathrm{M}+\mathrm{H}-\mathrm{C}_{2} \mathrm{H}_{4} \mathrm{O}_{4}\right]^{+}$} & 220.1338 & 220.1335 & -1.4 \\
\hline $\mathrm{C}_{13} \mathrm{H}_{16} \mathrm{NO}^{+}$ & {$\left[\mathrm{M}+\mathrm{H}-\mathrm{C}_{2} \mathrm{H}_{6} \mathrm{O}_{5}\right]^{+}$} & 202.1232 & 202.1230 & -1.0 \\
\hline $\mathrm{C}_{12} \mathrm{H}_{17} \mathrm{O}_{2}^{+}$ & {$\left[\mathrm{M}+\mathrm{H}-\mathrm{C}_{3} \mathrm{H}_{5} \mathrm{NO}_{4}\right]^{+}$} & 193.1222 & 193.1225 & +1.5 \\
\hline $\mathrm{C}_{12} \mathrm{H}_{15} \mathrm{O}^{+}$ & {$\left[\mathrm{M}+\mathrm{H}-\mathrm{C}_{3} \mathrm{H}_{7} \mathrm{NO}_{4}\right]^{+}$} & 175.1123 & 175.1115 & -4.7 \\
\hline $\mathrm{C}_{11} \mathrm{H}_{13} \mathrm{O}^{+}$ & {$\left[\mathrm{M}+\mathrm{H}-\mathrm{C}_{4} \mathrm{H}_{9} \mathrm{NO}_{4}\right]^{+}$} & 161.0966 & 161.0965 & -0.6 \\
\hline
\end{tabular}




\begin{tabular}{|c|c|c|c|c|c|c|c|}
\hline $\begin{array}{c}\text { Measured mass } \\
\mathbf{m} / \mathbf{z}\end{array}$ & $\begin{array}{c}\text { Retention time } \\
\text { (min) }\end{array}$ & $\begin{array}{c}\text { Area } \\
(\%)\end{array}$ & Elemental composition & $\begin{array}{c}\text { Theorical mass } \\
\mathbf{m} / \mathbf{z}\end{array}$ & $\begin{array}{l}\text { Error } \\
(\mathrm{ppm})\end{array}$ & Product Name & i-FIT \\
\hline \multicolumn{8}{|c|}{ Expected products of control artificial seawater } \\
\hline 312.1449 & 2.21 & 100 & $\mathrm{C}_{15} \mathrm{H}_{22} \mathrm{NO}_{6}^{+}$ & 312.1447 & +0.7 & Domoic acid & - \\
\hline \multicolumn{8}{|c|}{ Expected products of irradiated artificial seawater } \\
\hline 312.1449 & 1.90 & 6.51 & $\mathrm{C}_{15} \mathrm{H}_{22} \mathrm{NO}_{6}^{+}$ & 312.1447 & +0.7 & Isodomoic acid & - \\
\hline 312.1449 & 1.98 & 13.08 & $\mathrm{C}_{15} \mathrm{H}_{22} \mathrm{NO}_{6}^{+}$ & 312.1447 & +0.7 & Isodomoic acid & - \\
\hline 312.1447 & 2.09 & 10.81 & $\mathrm{C}_{15} \mathrm{H}_{22} \mathrm{NO}_{6}^{+}$ & 312.1447 & +0.0 & Domoic acid & - \\
\hline 312.1449 & 2.18 & 50.54 & $\mathrm{C}_{15} \mathrm{H}_{22} \mathrm{NO}_{6}^{+}$ & 312.1447 & +0.7 & Isodomoic acid & - \\
\hline 312.1448 & 2.26 & 19.06 & $\mathrm{C}_{15} \mathrm{H}_{22} \mathrm{NO}_{6}{ }^{+}$ & 312.1447 & +0.4 & Isodomoic acid & - \\
\hline \multicolumn{8}{|c|}{ Unexpected products of irradiated artificial seawater } \\
\hline \multirow{5}{*}{268.1550} & \multirow{5}{*}{2.54} & \multirow{5}{*}{87.01} & $\mathrm{C}_{15} \mathrm{H}_{18} \mathrm{~N}_{5}^{+}$ & 268.1562 & -4.5 & - & 21.6 \\
\hline & & & $\mathrm{C}_{15} \mathrm{H}_{21} \mathrm{~N}_{2} \mathrm{ONa}^{+}$ & 268.1552 & -0.7 & - & 23.3 \\
\hline & & & $\mathrm{C}_{14} \mathrm{H}_{22} \mathrm{NO}_{4}^{+}$ & 268.1549 & +0.4 & $\begin{array}{c}\text { Decarboxylated } \\
\text { domoic acid }\end{array}$ & 24.1 \\
\hline & & & $\mathrm{C}_{13} \mathrm{H}_{19} \mathrm{~N}_{5} \mathrm{Na}^{+}$ & 268.1538 & +4.5 & - & 25.0 \\
\hline & & & $\mathrm{H}_{17} \mathrm{~N}_{14} \mathrm{O}_{2} \mathrm{Na}^{+}$ & 268.1557 & -2.6 & - & 34.7 \\
\hline \multirow{6}{*}{290.1368} & \multirow{6}{*}{2.54} & \multirow{6}{*}{12.99} & $\mathrm{C}_{14} \mathrm{H}_{21} \mathrm{NO}_{4} \mathrm{Na}^{+}$ & 290.1368 & 0.0 & $\begin{array}{c}\text { Decarboxylated } \\
\text { domoic acid }\end{array}$ & 9.6 \\
\hline & & & $\mathrm{C}_{14} \mathrm{H}_{18} \mathrm{~N}_{4} \mathrm{O}_{3}{ }^{+}$ & 290.1379 & -3.8 & - & 11.0 \\
\hline & & & $\mathrm{C}_{12} \mathrm{H}_{16} \mathrm{~N}_{7} \mathrm{O}_{2}^{+}$ & 290.1365 & +1.0 & - & 16.2 \\
\hline & & & $\mathrm{C}_{15} \mathrm{H}_{17} \mathrm{~N}_{5} \mathrm{Na}^{+}$ & 290.1382 & -4.8 & - & 16.3 \\
\hline & & & $\mathrm{C}_{13} \mathrm{H}_{22} \mathrm{O}_{7}^{+}$ & 290.1366 & +0.7 & - & 16.6 \\
\hline & & & $\mathrm{C}_{12} \mathrm{H}_{19} \mathrm{~N}_{4} \mathrm{O}_{3} \mathrm{Na}^{+}$ & 290.1355 & +4.5 & - & 17.4 \\
\hline
\end{tabular}

429 i-FIT: isotopic fit value. The lower the value, the better the fit. 
430 Table 3. Accurate mass measurement of decarboxylated domoic acid and its major fragment ions.

\begin{tabular}{cccc}
\hline Elemental composition & $\begin{array}{c}\text { Theorical mass } \\
\mathbf{m} / \mathbf{z}\end{array}$ & $\begin{array}{c}\text { Measured mass } \\
\mathbf{m} / \mathbf{z}\end{array}$ & $\begin{array}{c}\text { Error } \\
(\mathbf{p p m})\end{array}$ \\
\hline $\mathrm{C}_{14} \mathrm{H}_{21} \mathrm{NO}_{4} \mathrm{Na}^{+}$ & 290.1368 & 290.1368 & +0.0 \\
$\mathrm{C}_{14} \mathrm{H}_{22} \mathrm{NO}_{4}{ }^{+}$ & 268.1549 & 268.1550 & +0.4 \\
$\mathrm{C}_{14} \mathrm{H}_{20} \mathrm{NO}_{3}{ }^{+}$ & 250.1443 & 250.1445 & +0.8 \\
$\mathrm{C}_{13} \mathrm{H}_{20} \mathrm{NO}_{2}{ }^{+}$ & 222.1494 & 222.1493 & -0.5 \\
$\mathrm{C}_{13} \mathrm{H}_{1} \mathrm{NO}^{+}$ & 204.1388 & 204.1388 & 0.0 \\
$\mathrm{C}_{12} \mathrm{H}_{18} \mathrm{~N}^{+}$ & 176.1439 & 176.1440 & +0.6 \\
$\mathrm{C}_{11} \mathrm{H}_{17}{ }^{+}$ & 149.1330 & $149.1325^{*}$ & -3.4 \\
\hline
\end{tabular}

$431 *$ Molecular ion found in noise, by eliminating $\mathrm{CO}_{2}$ molecule from $\mathrm{C}_{12} \mathrm{H}_{17} \mathrm{O}_{2}{ }^{+}$, the lowest fragment 432 ion of domoic acid including $\mathrm{O}_{2}(\mathrm{~m} / \mathrm{z}$ 193.1229).

433 
$436 \quad$ Figure 1

437 Structure of domoic acid.

439 Figure 2

440 Representative profiles mass spectrum with low energy collision in $\mathrm{MS}^{\mathrm{E}}$ mode (parent ion of 441 domoic acid)(A) and mass spectrum with hight energy collision in $\mathrm{MS}^{\mathrm{E}}$ mode (fragment ions of 442 domoic acid)(B).

$443 \quad$ Figure 3

444 Possible fragmentation pathway for domoic acid.

$446 \quad$ Figure 4

447 Separation of DA and GLF by optimized UHPLC method. DA and GLF Extraction Chromatogram 448 and Total Ion Chromatogram. Compound a corresponds to DA at $2.22 \mathrm{~min}$. Compound b 449 corresponds to GLF at 2.39 min and compounds c, d, e,f , g correspond to plastics pollutants. 450 451 $452 \quad$ Figure 5

453 LC-MS/MS chromatogram after extraction at m/z $312.14 \pm 0.02 \mathrm{Da}$, domoic acid in seawater, 454 before (A) and after (B) UV-irradiation as described in Materials and methods.

$456 \quad$ Figure 6

457 Probability of the position of the transformation by photodegradation of domoic acid. Weighted \% 458 of the spectral data supporting photodegradation transformation at the position shown. 
$460 \quad$ Figure7

461 Representative profiles of MS (A) and MS/MS (B) analysis of the decarboxylated domoic acid.

462 
463 Figure 1

464

465

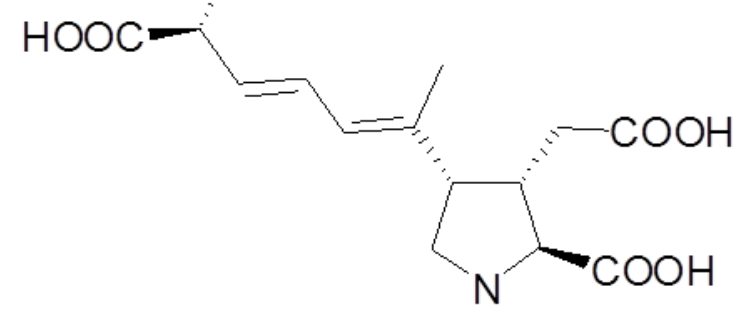

466

467 
468 Figure 2

469

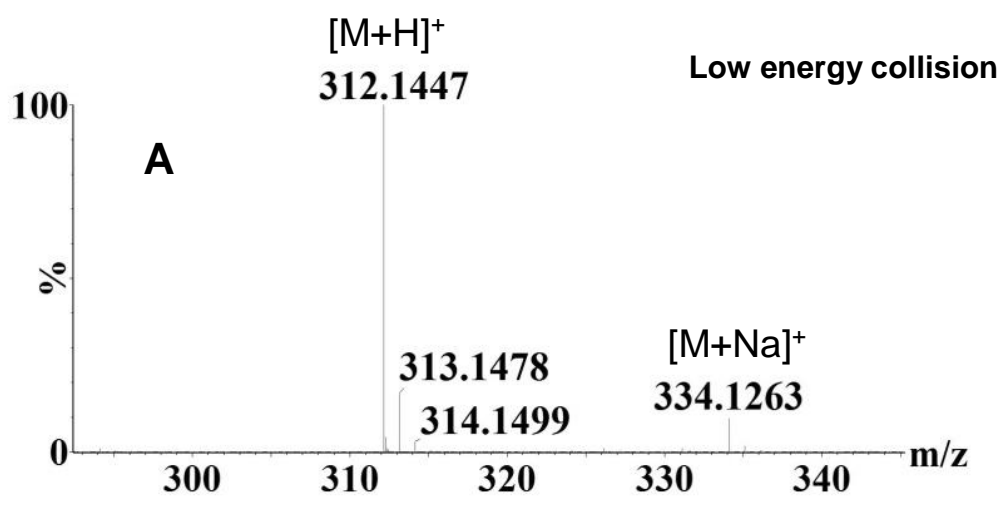

Hight energy collision

$-\mathrm{CH} 2 \mathrm{O} 2$

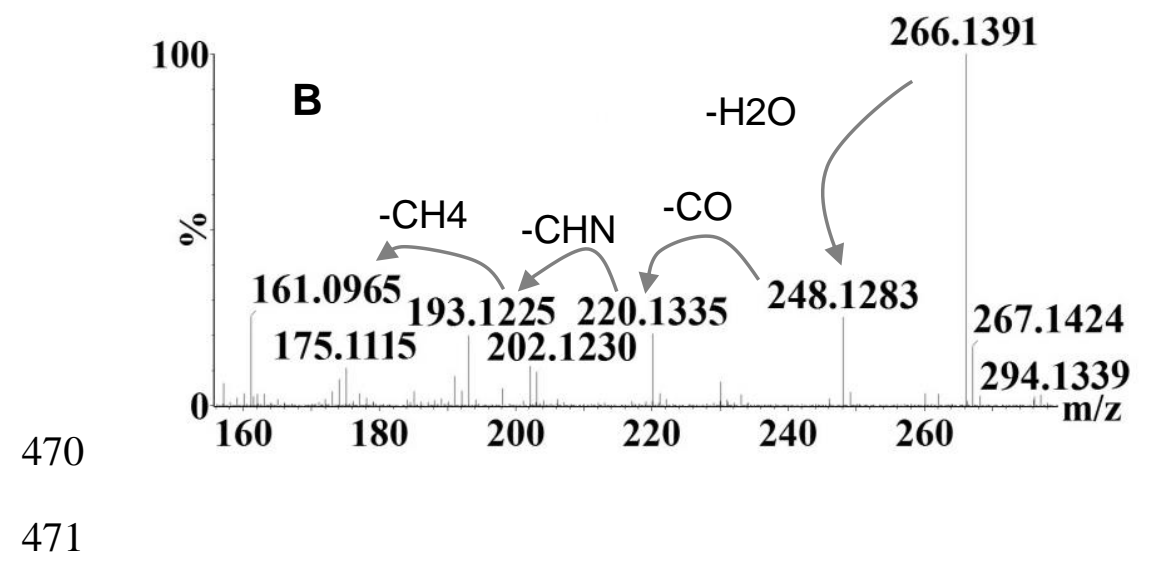


$472 \quad$ Figure 3

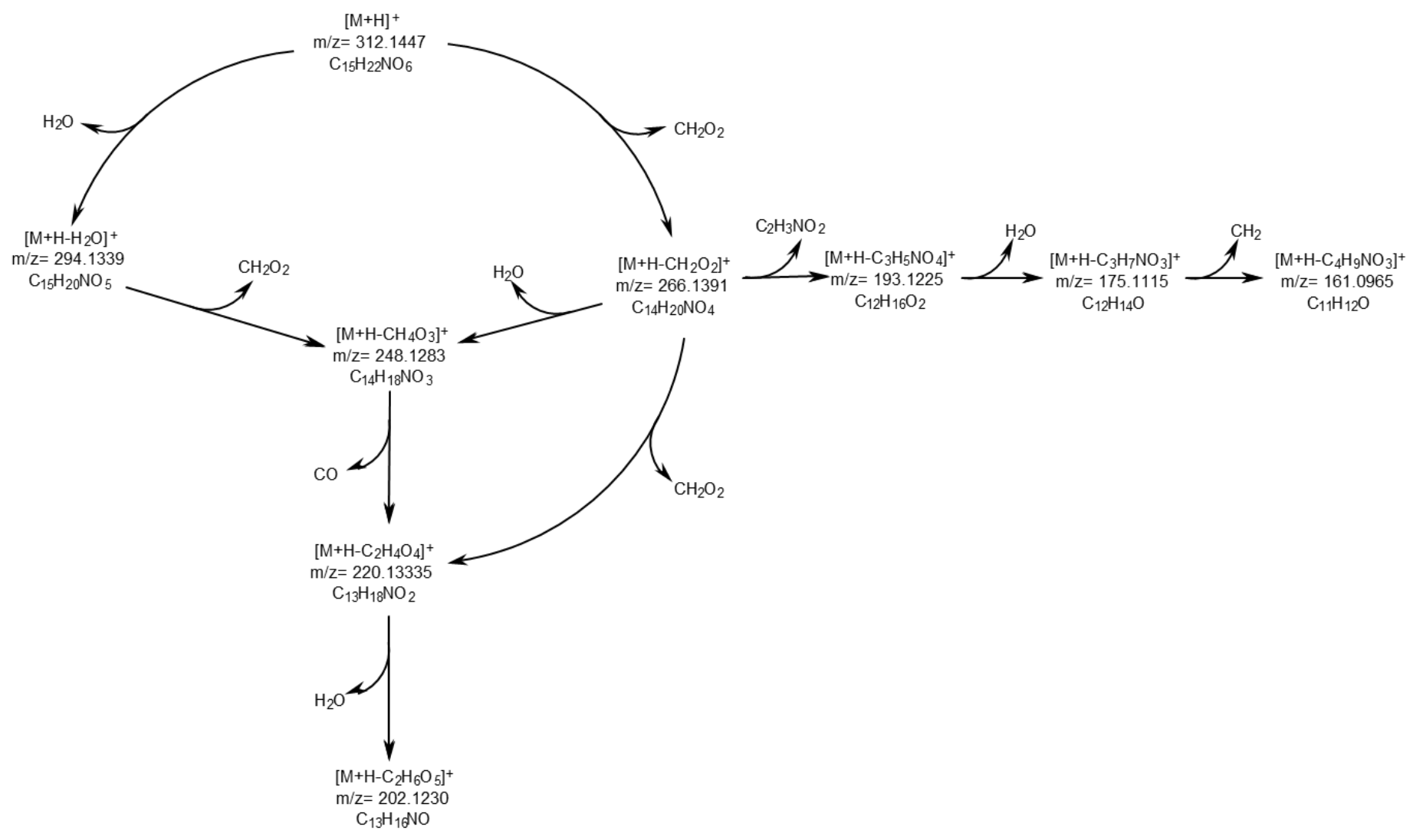


$474 \quad$ Figure 4

b

476
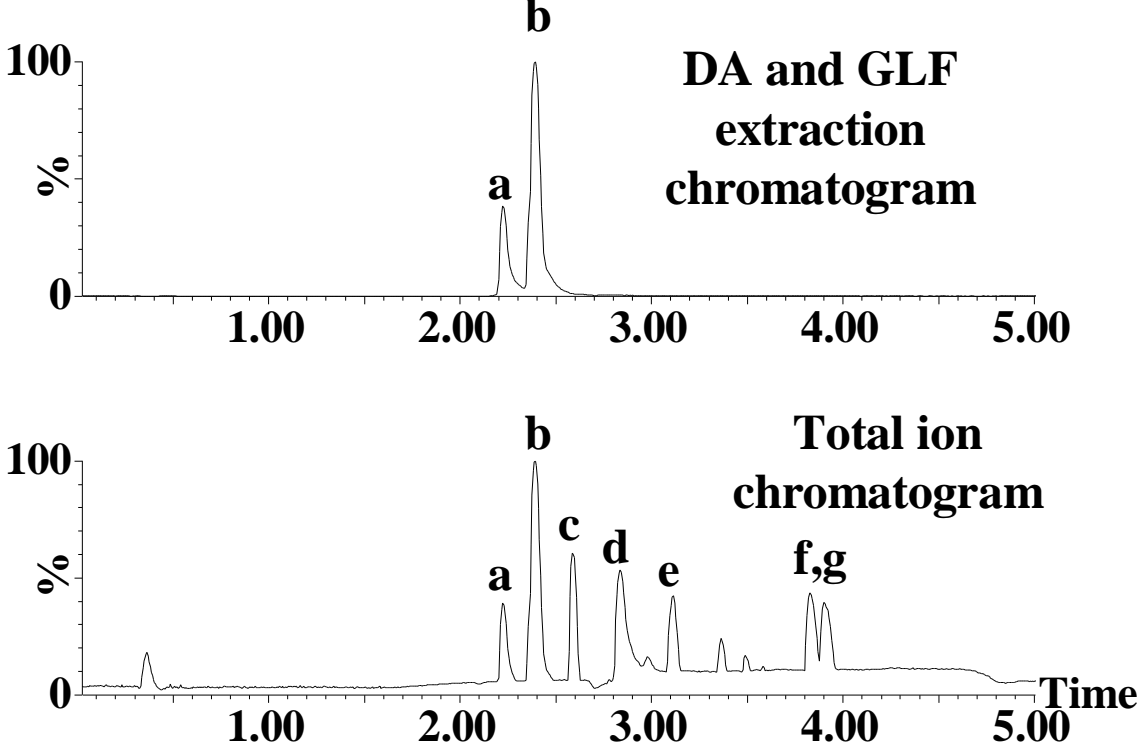
477 Figure 5

478

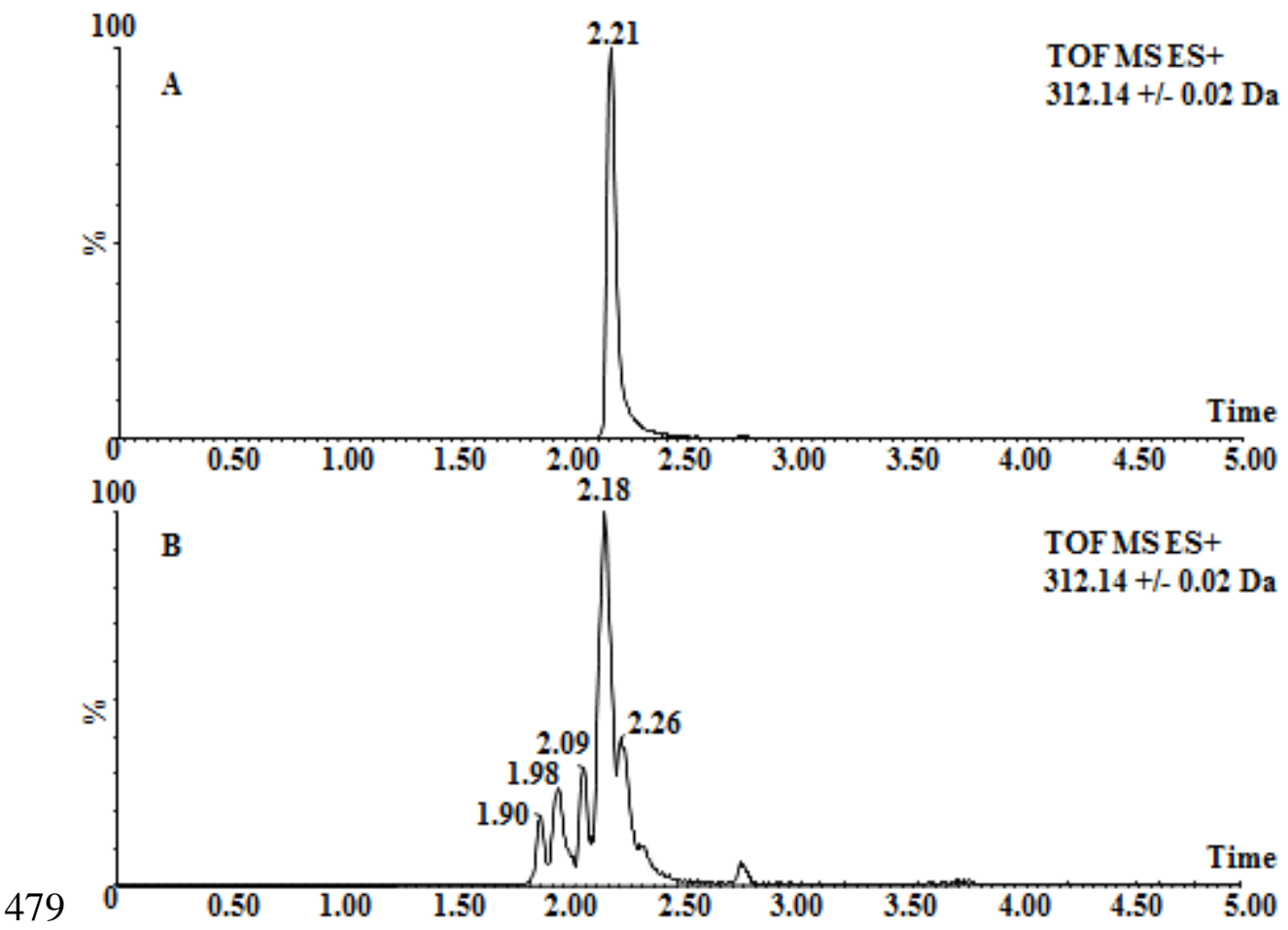

480

481 
482 Figure 6

483

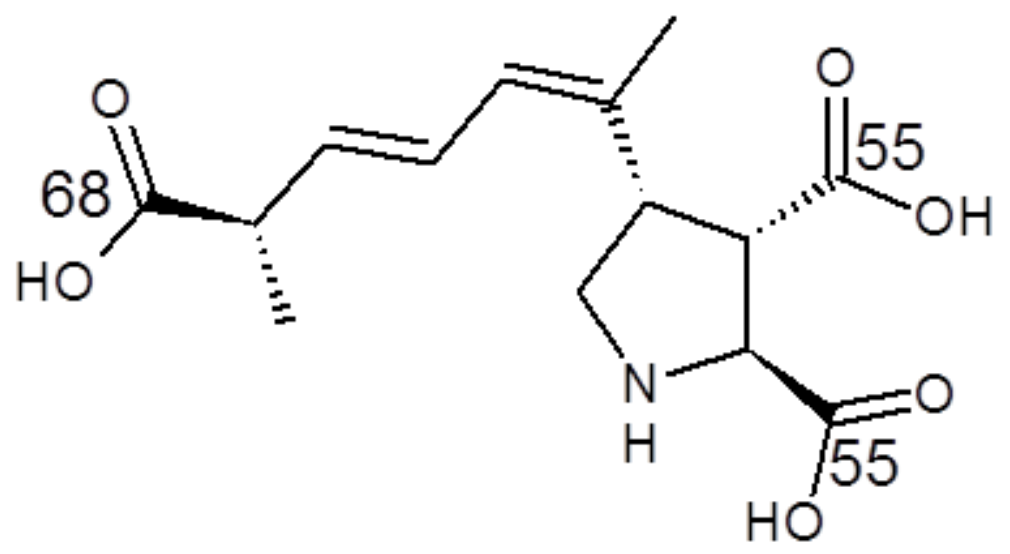

484

485 
486 Figure 7

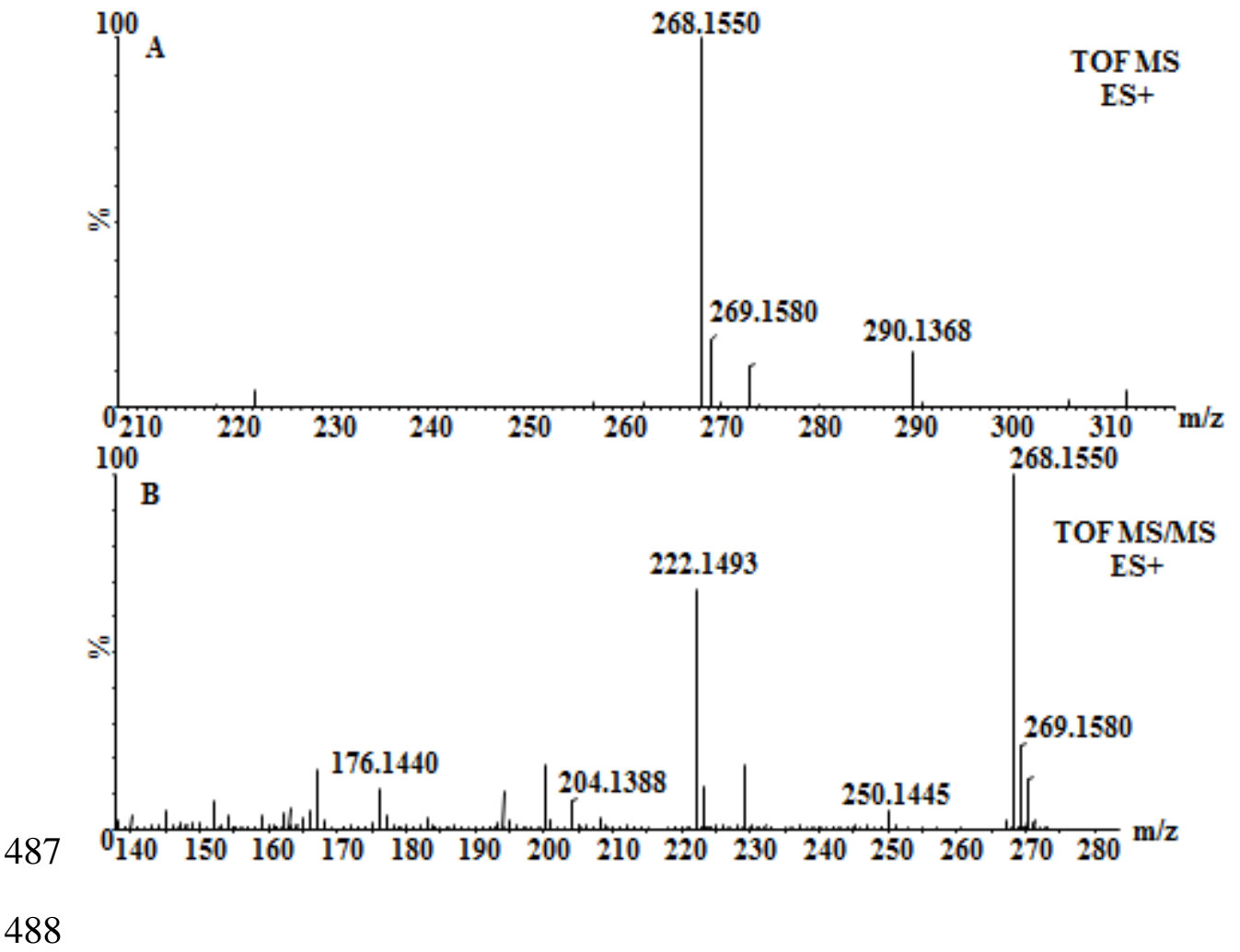

